\title{
The secondary memory component in the Brown-Peterson paradigm
}

\author{
D. J. MURRAY \\ Queen's University, Kingston, Ontario K7L 3N6, Canada
}

\begin{abstract}
Previous work has suggested that after about 6 sec of distraction activity, retrieval in the Brown-Peterson paradigm is probably from secondary memory. Support for this view comes from the present demonstrations that (1) the serial position curve in this paradigm shows a strong primacy effect and (2) variables known to influence secondary memory, such as imagery value and level of processing, also selectively influence recall in the Brown-Peterson paradigm.
\end{abstract}

Recently, investigators have shown that forgetting in the Brown-Peterson paradigm can have its locus either in the short-term store component of the task or in the long-term store component of the task (Chechile \& Butler, 1975; Turvey \& Weeks, 1975). Since the paradigm was originally devised by Brown (1958) and Peterson and Peterson (1959) to investigate short-term or primary memory, psychologists are now obliged to recognize that forgetting in this paradigm can also be from long-term or secondary memory. Further evidence supporting this view has been given by Crowder (1976), in his review of proactive interference effects in the paradigm, and Baddeley and Scott (1971) have suggested that "the Peterson technique comprises two components, a primary memory component which decays within $6 \mathrm{sec}$ and a more stable secondary memory component"' (p. 275). The purpose of the present study was to show that, in two other respects, forgetting in this paradigm may be shown to be in part from longterm memory. First, it is demonstrated that variables such as imagery value (Paivio, 1971) and depth of processing (Craik \& Tulving, 1975), known to affect secondary memory, also affect retention in the BrownPeterson paradigm, even after $30 \mathrm{sec}$ of interference. Second, it is shown, by an analysis of serial position data, that recall of four words following a distraction task yields a primacy effect, a phenomenon known from work on free recall to be associated with secondary memory.

\section{METHOD}

\section{General}

There were three experiments, which differed only in terms of one of the variables, and which will therefore be described together. Experiment 1 investigated recall after 6 or $30 \mathrm{sec}$ of interference following perception of four words that were read silently, whispered, or spoken aloud (vocalized). Experiment 2

This research was supported by National Research Council of Canada Grand AO-126. The author wishes to thank L. Zajac and $\mathrm{A}$. Chenier for research assistance. Reprint requests should be addressed to D. J. Murray, Department of Psychology, Queen's University, Kingston, Ontario K7L 3N6, Canada. investigated recall after 6 or $30 \mathrm{sec}$ of interference following perception of four words that were of low, medium, or high imagery value. Experiment 3 investigated recall after 6 or $30 \mathrm{sec}$ of interference following perception of four words that were processed to different "levels."

\section{Experiment 1}

Sixty monosyllabic English words, each of which was known to have several rhyming words, but none of which rhymed with each other, were divided into 15 lists of four words each. The word frequencies varied from 91 to 1 on the Kučera-Francis (1967) scale, but the words were so combined that each list of four words had a mean frequency varying between 13.25 and 75.5. Typical lists were HUT, MATE, BAY, HOWL and DREAM, VAN, TIP, JAW. Each word was written on a $12.5 \times 7.5 \mathrm{~cm}$ index card.

On arrival, subjects were instructed that they would see four words presented for $2 \mathrm{sec}$ each. The experimenter showed each card for this period. On some trials, the subjects read the words silently, on others, they whispered the words aloud, and on others, they voiced the words aloud. Exactly $2 \mathrm{sec}$ after the last of the four items, they were asked to count backward by threes from a given three-digit number until they were told to stop. Subjects then recalled the words verbally. Each subject came for one session. In each session, the first three lists were practice lists; then there were four lists each read under each of the three conditions "read," "whisper," and "voice." The order of the conditions was counterbalanced across subjects, as was the use of each word list in each vocalization condition.

There were two groups of subjects, one that performed the counting task (the distraction task) for $6 \mathrm{sec}$ and one for $30 \mathrm{sec}$. There were 18 subjects in each group. All subjects were drawn from a large class in introductory psychology and Queen's University.

\section{Experiment 2}

For this experiment, 60 words, all of Thorndike-Lorge A frequency, were chosen from the imagery norms of Paivio, Yuille, and Madigan (1968). Twenty words were of high imagery value (imagery ratings of 6.2 to 6.4 ), 20 words of medium imagery value (imagery ratings of 4.5 to 5.07), and 20 words were of low imagery value (imagery ratings of 2.00 to 3.13 ). Within each group, five lists of four words each were constructed in such a way as to make the mean imagery value of each list approximately constant and to avoid adjacent items that seemed to be easily associated semantically. Typical lists were: high imagery, PALACE, BOTTLE, STEAM, PUPIL; medium imagery, VESSEL, GIFT, CREATURE, ANGER; low imagery, FATE, EVENT, CUSTOM, FREEDOM.

The procedure with subjects was as for Experiment 1, but all subjects read the words silently at presentation. In each 
session, the first three lists were practice lists, then there were four lists under each of the three conditions, high, low, or medium imagery. As in Experiment 1, the order in which the three kinds of lists were examined was counterbalanced across the experiment.

There were two groups of subjects with 18 students from introductory psychology in each: One group did the distraction task for $6 \mathrm{sec}$ and the other, for $30 \mathrm{sec}$.

\section{Experiment 3}

The 60 words used for Experiment 1 were also used for Experiment 3. On each trial, four words were presented for 2 sec each. At the same time, the experimenter asked a question about the word, to which the answer was always "yes" or "no." There were three kinds of question. The "case" question was: Is the word in capital letters? The "rhyme" question consisted of showing the to-be-remembered (TBR) word along with another word printed in red; the subject had to say whether the two words rhymed. The "sentence" question consisted of showing the TBR word along with a sentence with a gap; the subject had to say if the TBR word would approximately fill the gap. For example, if the TBR word was VAN, the subject saw "They moved the furniture in a , or "He looked at his to see what time it was." In the first instance, VAN is an appropriate word to fill in the gap, and the subject would reply "yes." In the second instance, VAN is not an appropriate filler word, and the subject would reply "no." The numbers of "yes" and "no" answers for each word were equal across the whole experiment.

After four words had been presented and responded to appropriately, counting backward ensued, followed by the recall of the four words. As in Experiments 1 and 2, there were two groups of subjects, one group doing the distraction task for $6 \mathrm{sec}$, the other for $30 \mathrm{sec}$. There were 18 subjects in each group, all drawn from the class in introductory psychology. Each subject did four trials under each of the case, rhyme, and sentence conditions; the order in which these were carried out was counterbalanced over the experiment, as was the way in which each word list was studied under each level-of-processing condition. It is assumed that the amount of mental processing required to answer each question increases in the order, case, rhyme, sentence (Craik \& Tulving, 1975).

\section{RESULTS}

\section{Experiment 1}

Recall after $30 \mathrm{sec}$ (mean $=2.7$ items) was only slightly lower than recall after $6 \sec (2.9$ items), and the difference was not statistically significant. Although there was a trend for the mean number of items recalled to increase as vocalization increased (silent reading, 2.80 items; whispering, 2.83 items; voicing, 2.89 items), the effect was not significant. On the other hand, there was a clear effect of serial position $[\mathrm{F}(3,102)=36.46$, $\mathrm{p}<.001]$. At both retention intervals, recall was highest for the first TBR items in the list and decreased across serial position. There were no significant interactions in this experiment. The serial position curves under each of the six conditions (vocalization, retention interval) are shown in Figure 1(a).

\section{Experiment 2}

Recall after $30 \mathrm{sec}$ (2.57 items) was slightly higher than recall after $6 \mathrm{sec}$ ( 2.48 items), but this difference

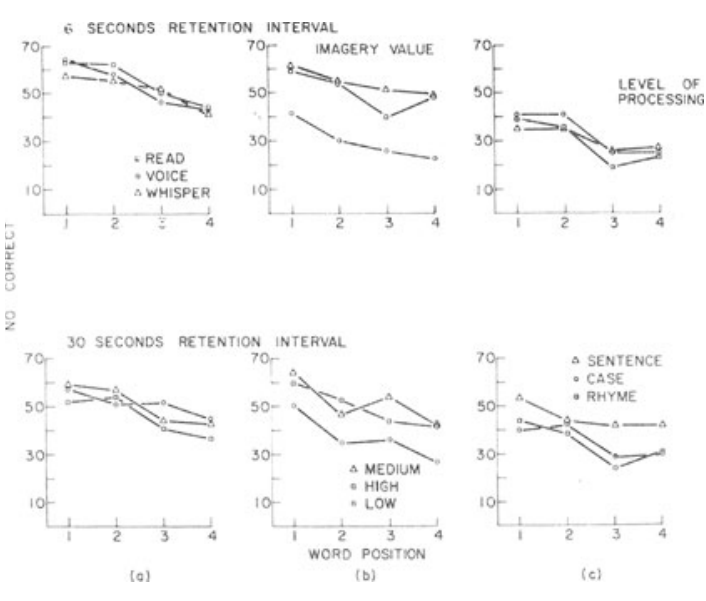

Figure 1. Serial position curves for recall after $6 \mathrm{sec}$ (top) or $30 \mathrm{sec}$ (bottom) of distraction activity. The results for Experiments 1, 2, and 3 are shown in Parts a, b, and c, respectively.

failed to reach statistical significance. The effect of imagery value was significant $[\mathrm{F}(2,68)=25.88$, $p<.001]$. The mean number of high-imagery items recalled was 2.79 , of medium-imagery items, 2.93 , and of low-imagery items, 1.87 . Clearly, most of the imagery effect is accounted for by the poor recall of the lowimagery words. The effect of serial position was also significant $[F(3,103)=29.05, p<.001]$; as in Experiment 1 , recall decreased across serial position. No interactions were significant. The serial position curves are shown in Figure 1(b).

\section{Experiment 3}

Recall after $30 \mathrm{sec}$ (2.12 items) exceeded recall after $6 \mathrm{sec}$ (1.72 items), but the difference failed to reach the .05 level of significance $[F(1,34)=3.11$, $p=.08]$. The effect of level of processing was significant $[F(2,68)=4.74, p=.012]$; the total number of words recalled that had been processed to the case level was 1.82 , the rhyme level yielded 1.76 , and the sentence level yielded 2.19 items. That sentence processing yields recall superior to that of case or rhyme processing confirms the findings of Craik and Tulving (1975), but rhyme processing was not found to lead to recall exceeding that of case processing. I suspect that this failure was actually an artifact of the present paradigm: In case processing, the subject only sees one card with one word on it, whereas in rhyme processing, the subject sees two cards each with a different word. It is possible that, at recall, memories of the rhyming word were confused with memories for the TBR word; the desired result might have been obtained by asking the subject himself to produce a rhyme for the TBR word. Coming back to the main results, however, the effect of serial position was significant $[F(3,102)=21.12, p<.001]$. As before, recall decreased across serial position. No 
interactions were significant. The serial position curves for Experiment 3 are shown in Figure 1(c).

\section{DISCUSSION}

It is clear that at both the 6 -sec and 30 -sec retention intervals, recall was higher for the initial items of the list than it was for the end items of the list in all three experiments. It is possible that some intralist rehearsal gave particular benefit to the first items, as it does in free recall (Rundus \& Atkinson, 1970). It is also possible that the final items of the list did not persist in primary memory long enough for transfer to secondary memory, because the distractor task interfered with rehearsal of those items. The combination of these two processes would lead to a primacy effect rather than a recency effect, and the fact that the primacy effect persisted for as long as $30 \mathrm{sec}$ would indicate that the initial items had gone into secondary memory.

In view of the fact that vocalization at presentation has been shown to positively enhance primary memory but not secondary memory (Murray, Leung, \& McVie, 1974), it could also be argued that, since there was little effect of vocalization on retention in Experiment 1, whereas there were strong effects of imagery and depth processing in Experiments 2 and 3, retention beyond $6 \mathrm{sec}$ in this paradigm is predominantly from secondary memory. A minor flaw with this argument is that the distractor task itself was vocalized. The vocalized responding may, therefore, by modality-specific interference, have reduced the recall of vocalized lists in particular. The evidence from Experiment 1 that there is little of a primary memory component after 6 or $30 \mathrm{sec}$ of distraction is, therefore, only tentative.

Recall after $30 \mathrm{sec}$ of distraction activity was nonsignificantly better than recall after $6 \mathrm{sec}$ of distraction activity in Experiments 2 and 3. Erdelyi and Kleinbard (1978) have shown that reminiscence of this kind is most likely to occur if the material is visual. Perhaps subjects used imagery to encode the items in Experiments 2 and 3, where the mode of presentation was such as to encourage this kind of treatment.

\section{REFERENCES}

Baddeley, A. B., \& ScotT, D. Short term forgetting in the absence of proactive interference. Quarterly Journal of Experimental Psychology, 1971, 23, 275-283.

Brown, J. Some tests of the decay theory of immediate memory. Quarterly Journal of Experimental Psychology, 1958, 10, 12-21.

Chechile, R., \& Butler, K. Storage and retrieval changes that occur in the development and release of PI. Journal of Verbal Learning and Verbal Behavior, 1975, 14, 430-437.

Craik, F. I. M., \& Tulving, E. Depth of processing and the retention of words in episodic memory. Journal of Experimental Psychology: General, 1975, 104, 268-294.

Crowder, R. G. Principles of learning and memory. Hillsdale, N.J: Lawrence Erlbaum, 1976.

ERDELYI, M. H., \& KLEINBARD, J. Has Ebbinghaus decayed with time? The growth of recall (hypermnesia) over days. Journal of Experimental Psychology: Human Learning and Memory, 1978, 4, 275-289.

KUČERA, H., \& FRANCIS, W. N. Computational analysis of presentday American English. Providence, R.I: Brown University Press, 1967.

Murray, D. J., Leung, C., \& McVie, D. F. Vocalization, primary memory, and secondary memory. British Journal of Psychology, 1974, 65, 403-413.

PAIvio, A. Imagery and verbal processes. New York: Holt, Rinehart, \& Winston, 1971.

Paivio, A., Yuille, J. C., \& Madigan, S. Concreteness, imagery, and meaningfulness values for 925 nouns. Journal of Experimental Psychology Monographs, 1968, 76(1, Part 2).

Peterson, L. R., \& Peterson, M. J. Short-term retention of individual verbal items. Journal of Experimental Psychology, 1959, 58, 193-198.

Rundus, D., \& Atrinson, R. C. Rehearsal processes in free recall: A procedure for direct observation. Journal of Verbal Learning and Verbal Behavior, 1970, 9, 99-105.

TURVEY, M. T., \& WEEKs, R. A. Effects of proactive interference and rehearsal on the primary and secondary components of short-term retention. Quarterly Journal of Experimental Psychology, 1975, 27, 47-62.

(Received for publication September 28, 1978.) 